\title{
New generation traction power supply system and its key technologies for electrified railways
}

\author{
Qunzhan Li
}

Received: 17 December 2014/Revised: 9 January 2015/Accepted: 9 January 2015/Published online: 29 January 2015

(C) The Author(s) 2015. This article is published with open access at Springerlink.com

\begin{abstract}
Unlike the traditional traction power supply system which enables the electrified railway traction substation to be connected to power grid in a way of phase rotation, a new generation traction power supply system without phase splits is proposed in this paper. Three key techniques used in this system have been discussed. First, a combined co-phase traction power supply system is applied at traction substations for compensating negative sequence current and eliminating phase splits at exits of substations; design method and procedure for this system are presented. Second, a new bilateral traction power supply technology is proposed to eliminate the phase split at section post and reduce the influence of equalizing current on the power grid. Meanwhile, power factor should be adjusted to ensure a proper voltage level of the traction network. Third, a segmental power supply technology of traction network is used to divide the power supply arms into several segments, and the synchronous measurement and control technology is applied to diagnose faults and their locations quickly and accurately. Thus, the fault impact can be limited to a minimum degree. In addition, the economy and reliability of the new generation traction power supply system are analyzed.
\end{abstract}

Keywords New generation traction power supply system · Combined co-phase power supply · Bilateral power supply - Segmental power supply technology · Synchronous measurement and control

The Chinese version of this paper was published in Journal of Southwest Jiaotong University (2014) 49(4).

Q. Li $(\bowtie)$

School of Electrical Engineering, Southwest Jiaotong University, Chengdu 610031, China

e-mail: lqz3431@263.net

\section{Introduction}

The development of the high-speed railway in China where the mileages has been increased substantially in recent years has shown the advantages of using industrial frequency (50/ $60 \mathrm{~Hz}$ ) single-phase AC traction power supply system [1]. However, the phase split in such a system becomes the breakpoint of power supply to the train [2-4], which could affect the power traction generation. It is also the point where the mechanical failure could occur so that the system reliability is degraded. In Germany and its neighboring countries, the low-frequency single-phase AC power supply system is adopted. Although the system can realize co-phase traction power supply without phase splits, the high cost limits its worldwide applications. It is concluded that in an electrified railway traction power supply system, avoiding phase splits while keeping investment costs down is one of the most important factors to be considered.

One of the major developments on electric traction systems for industrial frequency single-phase AC electrified railway is to replace the electrical locomotives of $\mathrm{AC} / \mathrm{DC}$ type with the electrical locomotives or MUs (multiple units) of AC/DC/AC type. Moreover, increasing the operation speed of a pantograph-catenary system from a few ten or a hundred kilometers per hour to more than two hundreds or three hundreds kilometers per hour marks another milestone in the development of high-speed railways. Unlike the traditional traction power supply system in which traction substations are connected to a power grid through phase rotation, a co-phase traction power supply system without phase splits can represent a next generation traction power supply system.

In the new traction power supply system described in this paper, three key techniques are developed, i.e., (1) A singlephase traction transformer (TT) and a compensation device with minimum capacity forms a combined co-phase traction 
power supply system in the substations, which can reduce the negative sequence current and eliminate phase splits. (2) A new bilateral power supply system is used to eliminate the phase split at section post, where a reactor connected in series with a feeder will reduce the influence of the equalizing currents on a power grid, and the power factor can be adjusted to ensure proper voltage level of the traction power network. (3) An approach of dividing a power supply arm into several segments and then applying synchronous measurement and control technique to ensure quick and accurate fault locating and fault diagnosing is proposed. By doing so, the effects of faults can be reduced to a great extent and thus the power traction network reliability and availability are able to be achieved.

\section{Combined co-phase power supply technology in traction substations}

A co-phase power supply system is a system that provides power for electrical locomotive and has the same voltage phase across all power supply arms [5-7]. Using the cophase power supply technology in traction substations, the phase split at the exit of a substation can be eliminated.

In general, TTs with connection type such as YNd11, three-phase to two-phase balance transformer, $\mathrm{Vv}, \mathrm{Vx}$, or single-phase connected transformer can be used in a cophase power supply system. They can be categorized as phase voltage and line voltage for easy analysis [6]. Considering that the single-phase connected transformer ( $\mathrm{Vv}$ or $\mathrm{Vx}$ ) has been widely used in the existing high-speed railway and newly-built railway in China, and it has the easiest wiring and the highest utilization rate of power supply capacity, the co-phase power supply scheme is made up of a single-phase connected transformer and a compensation device. Such a scheme can subsequently eliminate phase split, improve power quality by reducing negative sequence current [8, 9] and ultimately achieve the best match between the system and power supply capacity.

In a high-speed railway, if the power factor is equal to 1 , according to the formula 3.32 in Chapter 3.5 of [7] one can assume that $K_{\mathrm{N}}=1$ and $K_{\mathrm{c}}=0$. Then the required compensation capacity will be minimum and be equal to the traction load power if the transformer has three-phase to twophase balance connection and the negative sequence will be fully compensated. There are two approaches. One is the reactive power compensation approach, which can be passive such as SVC (Static Var Compensator) or active using IGBT or IGCT such as SVG (Static Var Generator, or STATCOM). Taking the Scott-connected transformer, for example, as shown in Fig. 1, the number of winding turns $n_{1}=n_{2}$, which is similar to the Scott connection with different winding turns used in Japan [10]. Another is the active

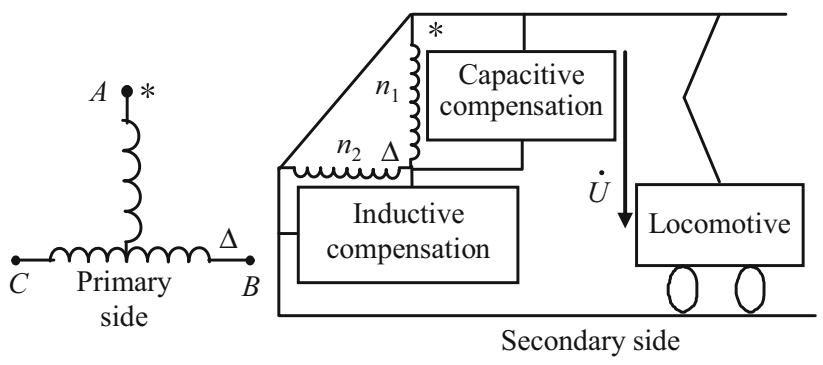

Fig. 1 Optimal reactive compensation based on balance transformer

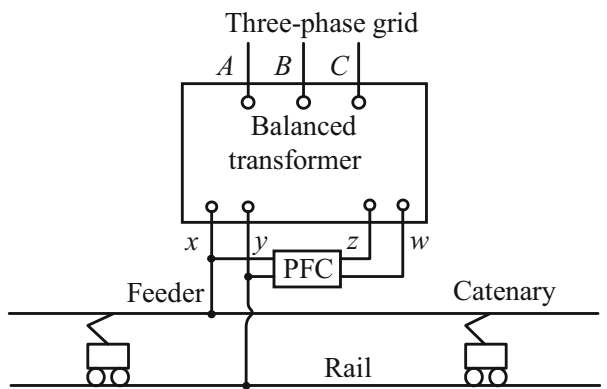

(a)

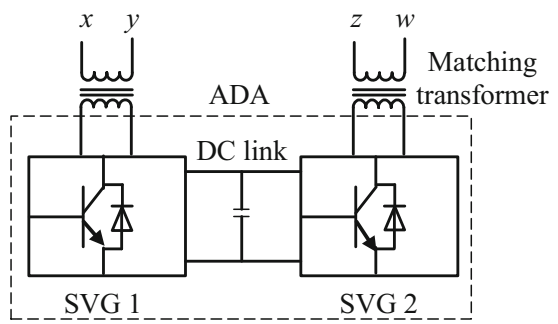

(b)

Fig. 2 Optimal power compensation based on active power compensation. a Balance transformer with the co-phase compensation device for active power compensation. b Phase compensation device

compensation approach shown in Fig. 2a. In this approach, the co-phase compensation device (CPD) works together with the balanced connection TT. The CPD (also called power flow controller, or PFC) is shown in Fig. 2b, which consists of a AC-DC-AC converter (ADA) and a matching transformer. When the power factor is equal to 1 , half of the active power of traction load power is provided by CPD, and the negative sequence current is thus eliminated. An ADA converter can be regarded as two back-to-back single-phase SVGs and the total capacity will be equal to the traction load power. In other words, the minimum reactive power capacity will be equal to the minimum active power capacity so as to achieve fully compensated negative sequence current.

\subsection{Scheme of the combined co-phase power supply}

It should be noted that firstly the reactive power compensation using balance transformer or $\mathrm{Vv}$ connected-TT as 
discussed before will occupy extra capacity of the TT while the active power compensation will not. On the contrary, the active power compensation will share the TT load and thus increase the system efficiency. Secondly, according to the national standard, a certain amount of negative sequence power is allowed in power system [11]. Thirdly, a balanced transformer is most effective and economic in compensating the negative sequence. Based on the above considerations, two schemes of combined co-phase power supply are proposed: One is the single-phase and three-phase combined co-phase supply system comprising a single-phase TT and a high-voltage three-phase matching transformer; another is the single-phase and single-phase combined co-phase supply system comprising a single-phase TT and a high-voltage single-phase matching transformer.

The combined co-phase supply traction substation consists of a TT and a CPD which includes a high-voltage matching transformer (HMT), a ADA, a traction matching transformer (TMT), and an inductor (L). The TT has the single-phase connection. If the single-phase and threephase combined co-phase power supply scheme is considered, the HMT will have YNd11 connection and will constitute a balanced connection together with the singlephase TT. In this case, the phase difference between the port of ADA and the port of TT is $90^{\circ}$. If a single-phase and single-phase combined co-phase power supply scheme is considered, the single-phase HMT together with the TT will constitute a balanced connection, forming the Scott connection with different winding turns, and the phase difference between ports is also $90^{\circ}$. In the latter scheme, the output port of the ADA will be connected to the primary side of the TMT and subsequently produce a voltage of the same frequency and phase as those of the TTs. Moreover, the output voltage at the secondary side of the TT will have the same frequency and phase as those at the secondary side of the TMT, and both sides are connected with the traction bus in the substation.

Comparing Fig. 2 with Figs. 3 or 4, it can be found that a TMT can be saved in the scheme of the combined cophase power supply; consequently the cost and space will be reduced, and thus the system efficiency will be increased. Furthermore, with the recent development of modular multilevel converter (MMC) technology, an ADA can be connected directly to the traction bus, which will result in further eliminating the need for TMT.

\subsection{Capacity calculation of the traction transformer} and the co-phase compensation device

Assume that the load power is $s$ (MVA), the TT power is $s_{\mathrm{T}}$ (MVA) and the CPD power is $s_{\mathrm{C}}$ (MVA), then

$s=s_{\mathrm{T}}+s_{\mathrm{C}}$

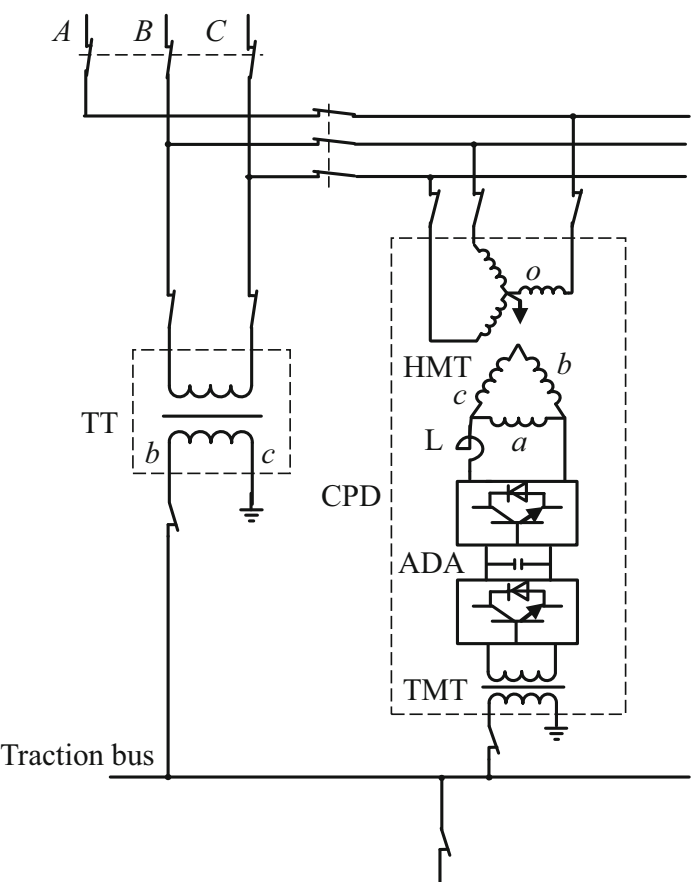

Fig. 3 Connection diagram of the combined co-phase supply system with a three-phase compensation module

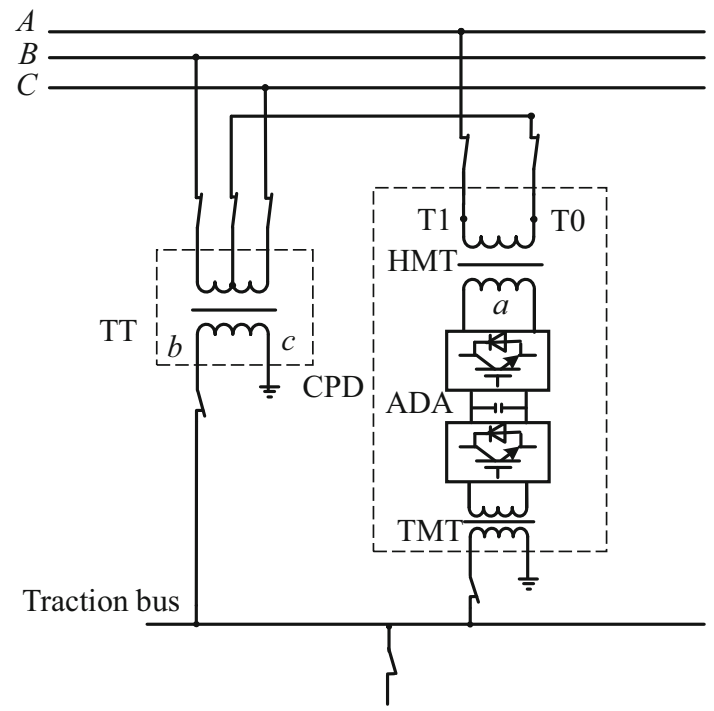

Fig. 4 Connection diagram of the combined co-phase supply system with a single-phase compensation module

With a balanced connection that is constituted by the HMT and the single-phase TT, as shown in Figs. 3 and 4; the negative sequence power $s$ is given by

$s^{-}=s_{\mathrm{T}}-s_{\mathrm{C}}$.

Equation (1) indicates that the CPD can share traction load while Eq. (2) indicates that it can reduce the negative sequence power. 
Three-phase voltage unbalance $u_{\varepsilon}$ can be described by the negative sequence power $s^{-}$and the power system short-circuit capacity $s_{\mathrm{d}}$ at the point of common coupling (PCC), and is defined as follows:

$u_{\varepsilon}=\frac{s^{-}}{s_{\mathrm{d}}} \times 100 \%$.

That is, if the three-phase voltage unbalance limit $u_{\varepsilon}(\%)$ and the system short-circuit capacity $s_{\mathrm{d}}$ (MVA) are known, then the negative sequence power allowable value $s_{\varepsilon}$ is

$s_{\varepsilon}=u_{\varepsilon} s_{\mathrm{d}} / 100$.

Considering Eq. (2), then

$s_{\varepsilon}=s^{-}=s_{\mathrm{T}}-s_{\mathrm{C}}$.

Combining Eq. (5) with Eq. (1) yields

$\left[\begin{array}{c}s_{\varepsilon} \\ s\end{array}\right]=\left[\begin{array}{cc}1 & -1 \\ 1 & 1\end{array}\right]\left[\begin{array}{l}s_{\mathrm{T}} \\ s_{\mathrm{C}}\end{array}\right]$.

Thus, $s_{\mathrm{T}}$ and $s_{\mathrm{C}}$ can be calculated as follows:

$\left[\begin{array}{l}s_{\mathrm{T}} \\ s_{\mathrm{C}}\end{array}\right]=\frac{1}{2}\left[\begin{array}{cc}1 & 1 \\ -1 & 1\end{array}\right]\left[\begin{array}{c}s_{\varepsilon} \\ s\end{array}\right]$.

Equation (6) indicates that $s_{\mathrm{C}}$ depends on $s$ and $s_{\varepsilon}$. Equation (4) indicates that $s_{\varepsilon}$ is proportional to the shortcircuit capacity. If a traction load is given, then the more powerful the power system is, the smaller the CPD capacity $s_{\mathrm{C}}$ will be. The vector diagram of negative sequence is shown in Fig. 5.It is evident that the negative sequence compensation capacity $s^{-}$is given by

$s_{\mathrm{C}}^{-}=s-s^{-}$.

Combining Eq. (1) with Eq. (2) gives $s_{\mathrm{C}}^{-}=2 s_{\mathrm{C}}$.

It can be concluded that the ability of providing negative sequence compensation in a co-phase power supply mode is to have two times the power of the CPD.

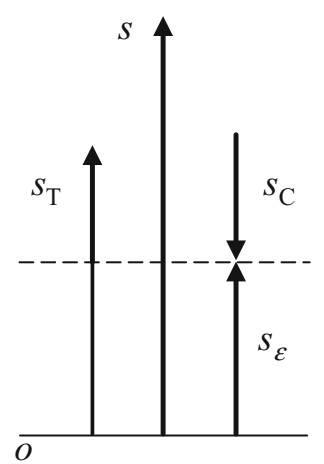

Fig. 5 Negative sequence vector diagram of combined co-phase traction power supply system

\subsection{Design method and procedure}

Step 1: Obtain the traction substation load process data $s_{\mathrm{L}}(t)$ through a power supply calculation method and then find the load power $s$ from the national standard [11] (95\% maximum probability value or maximum value). Based on three-phase voltage unbalance $u_{\varepsilon}(\%)$ according to the national standard and system shortcircuit capacity $s_{\mathrm{d}}(\mathrm{MVA})$, the negative sequence power allowable value can be calculated from Eq. (4)

Step 2: If $s_{\varepsilon} \geq s$, then $s_{\mathrm{C}} \leq 0$ from Eq. (6). It means that there is no need to have the CPD. In this case, the threephase voltage unbalance will meet the national standard and because of $s_{\mathrm{C}}=0$, the calculated capacity of the TT $s_{\mathrm{T}}=s$ from Eq. (1); then go to Step 5. If $s_{\varepsilon}<s$, then $s_{\mathrm{C}}>0$, that is, the CPD is required

Step 3: $s_{\mathrm{T}}$ and $s_{\mathrm{C}}$ are calculated using Eq. (6)

Step 4: The installed capacity $S_{c}$ is calculated based on the overload ability of the CPD, which depends on the overload ability of the ADA, and in general, its overload ability is lesser, so $S_{\mathrm{C}}=s_{\mathrm{C}}$ can be assumed

Step 5: The TT's installed capacity $S_{\mathrm{T}}$ is calculated based on its overload ability which in turn is calculated based on the temperature process and life loss associated with the load process [12]. For simplicity, the overload ability can be represented by an overload factor $k_{\mathrm{T}}$ which is the ratio of $S_{\mathrm{T}}$ corresponding to the national standard (95\% maximum probability value or maximum value) to the TT rated capacity. $k_{\mathrm{T}}(\geq 1)$ is generally given, so $S_{\mathrm{T}}=s_{\mathrm{T}} / k_{\mathrm{T}}$

Step 6: Output the results and calculation ends

Example 1 The three-phase voltage unbalance value $\left(u_{\varepsilon}\right)$ by the national standard is $2 \%$. The system short-circuit capacity $s_{\mathrm{d}}=1,500 \mathrm{MVA}$. Thus the negative sequence power allowable value $s_{\varepsilon}=30 \mathrm{MVA}$ from Eq. (4). The load power $s=50 \mathrm{MVA}$, which is obtained from the national standard specified value $(95 \%$ maximum probability value) based on the traction load process $s_{\mathrm{L}}(t)$. From Eq. (6), the calculated capacity of the TT $s_{\mathrm{T}}=40 \mathrm{MVA}$. The calculated capacity of the CPD $s_{\mathrm{C}}=10 \mathrm{MVA}$. If $k_{\mathrm{T}}=2$, then $S_{\mathrm{T}}=40 / 2=20$ MVA. A single-phase TT with installed capacity $20 \mathrm{MVA}$ is suggested. With $k_{\mathrm{C}}=1$, the installed capacity of the CPD $S_{\mathrm{C}}=s_{\mathrm{C}}=10 \mathrm{MVA}$. Therefore, the capacity of the single-phase TT is 20 MVA, and the capacity of the CPD is 10 MVA. From Eq. (7), the maximum compensation ability for the negative sequence is 20 MVA.

Example 2 If $u_{\varepsilon}=2 \% \quad(95 \%$ maximum probability value) and $s_{\mathrm{d}}=4,000 \mathrm{MVA}$, then the negative sequence power allowable value $s_{\varepsilon}=80 \mathrm{MVA}$ (Eq. (4)). If $s=120$ MVA, then $s_{\mathrm{T}}=100 \mathrm{MVA}$ based on Eq. (6), and the 
calculated capacity of the CPD $s_{\mathrm{C}}=20 \mathrm{MVA}$. If $k_{\mathrm{T}}=2$, then the TT's installed capacity $S_{\mathrm{T}}=100 / 2=50 \mathrm{MVA}$. A single-phase TT with an installed capacity of $50 \mathrm{MVA}$ is suggested. If $k_{\mathrm{C}}=1$, then $S_{\mathrm{C}}=s_{\mathrm{C}}=20 \mathrm{MVA}$. Therefore, the capacity of the single-phase TT is $50 \mathrm{MVA}$, and the capacity of the CPD is 20 MVA. Based on Eq. (7), the maximum compensation ability for the negative sequence is $40 \mathrm{MVA}$.

HMT and TMT are in series with ADA converter. They have the same load process. The overload abilities of HMT and TMT are higher than that of ADA converter and thus their installed capacities should be less than that of ADA converter.

Example 3 A practical example is a pilot project of cophase power supply system installed at Meishan substation [13], financed by a National Science and Technology Support Program. As shown in Fig. 2, the original substation has two power supply arms with the same capacity. If the combined co-phase power supply scheme shown in Fig. 4 is used, because $s_{\mathrm{T}}=s_{\mathrm{C}}$, then $s_{\varepsilon}=0$ can be derived from Eq. (6). Thus, $S_{\mathrm{C}}=s_{\mathrm{C}}=25 \mathrm{MVA}$ for Example 1, and $S_{\mathrm{C}}=s_{\mathrm{C}}=60 \mathrm{MVA}$ for Example 2; that is, a large compensation device capacity is required. Thus, the cost is high and the power supply capacity could be halved if the compensation device fails or in maintenance states.

The combined co-phase power supply technology meets the national standard requirement of allowable value of negative sequence power. It provides the best match between the CPD and the single-phase TT, which boosts the cost-effectiveness greatly. When the CPD needs to be repaired, the single-phase TT can work in the short-term overload so that the system operation will not be affected.

In the single-phase and single-phase combined co-phase power supply system, HMT can be installed together in one tank with the single-phase TT so that the space is saved. Such a system is suitable for new railway line construction. The single-phase and three-phase combined co-phase power supply system is more suitable for the existing substation conversion where the TT has $\mathrm{Vv}$ or $\mathrm{Vx}$ connection. In other words, by keeping the existing singlephase TT while adding a HMT with YNd11 connection and an ADA, a co-phase power supply system is realized.

Equation (6) or Fig. 5 has demonstrated that a CPD can work in two basic modes:

Mode I If the load power is less than or equal to twice the capacity of the CPD, and the TT and the CPD provide half load power, respectively, then the negative sequence current can be fully compensated, and the three-phase voltage unbalance will be zero. If the load power is greater than twice the capacity of the CPD which operates at the rated capacity, then the TT will supply the rest capacity required. In this case, although the negative sequence power will be produced, the three-phase voltage unbalance value will still be able to meet the requirements set by the national standard.

Mode II The CPD usually works in warm standby status and the output power is zero. Only when the load power $s$ is close to $\mathrm{r}$ allowable value $s_{\varepsilon}$, the CPD starts to work and consequently the negative sequence power is compensated. Again, the three-phase voltage unbalance value will be able to meet the requirements set by the national standard.

The two basic working modes of the CPD will bring different load processes to themselves and the TT, and result in different installed capacities as well. However, both modes can achieve the controlling of negative sequence and conform the national standard.

\section{A new bilateral power supply}

A bilateral power supply is not new and has been used since the former Soviet Union [14]. In this power supply system, breakers are used in section post to connect a traction network $\mathrm{TN}_{k}$ to its neighboring network $\mathrm{TN}_{k+1}$. Thus, two neighboring traction substations $\mathrm{SS}_{k}$ and $\mathrm{SS}_{k+1}$ provide bilateral power supply for $\mathrm{TN}_{k}$ and $\mathrm{TN}_{k+1}$. In a new bilateral power supply system proposed, reactors $L_{k}$ and $L_{k+1}$ are connected in series with traction feeders in substations $\mathrm{SS}_{k}$ and $\mathrm{SS}_{k+1}$, respectively, where singlephase $\mathrm{TT}_{k}$ and $\mathrm{TT}_{k+1}$ are being used, respectively. $\mathrm{SS}_{k}$ and $\mathrm{SS}_{k+1}$ are connected to the power system transmission line $\mathrm{ABC}$ at the points of common coupling, $\mathrm{PCC}_{k}$ and $\mathrm{PCC}_{k+1}$, respectively, as shown in Fig. 6.

An electrical connection mode between a power system and a traction substation is called external power supply mode, which depends on the topology of a power system

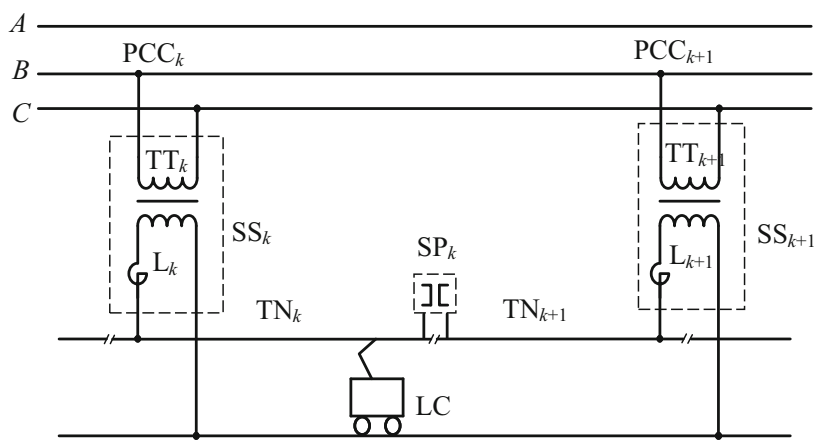

Fig. 6 Connection diagram of a bilateral power supply system 
and its relative position to the traction substation. In general, there are many connection types such as ring singleloop, ring double-loop, single source double-loop, radial connection, and so on. Figure 6 is a simplified schematic diagram of the ring single-loop, the ring double-loop, and the single source double-loop. This is a typical mode which is often called single-loop T connection.

\subsection{The equivalent circuit}

From Fig. 6, the equivalent circuit of a three-phase power system including the bilateral side can be obtained as shown in Fig. 7 where $Z_{\mathrm{d}}$ is the power system impedance per phase, $Z_{\mathrm{J} k}$ and $Z_{\mathrm{J} k+1}$ are the inlet wire impedances; $Z_{\mathrm{T} k}^{\prime}$ and $Z_{\mathrm{T} k+1}^{\prime}$ are the single-phase TT impedances, $Z_{q}^{\prime}$ is the traction network impedance, and $\mathrm{X}_{\mathrm{LT} k}^{\prime}$ and $\mathrm{X}_{\mathrm{LT} k+1}^{\prime}$ are the reactance of the series reactors (they all are converted to the power system); LC represents the electrical locomotive.

\subsection{The equalizing current}

Figure 8 is a diagram of the equalizing current. Taking phase $B$ (or $C$ ) in Fig. 7 as an example, $Z_{\mathrm{d}}$ and $Z_{\mathrm{q}}$ are the converted impedances of the power system transmission line and the traction power supply system (including the inlet wire), respectively; $I$ is the transport current, $I_{\mathrm{d}}$ is the power system transmission line current, and $I_{\mathrm{q}}$ is the traction power supply system current, so the equalizing current $I_{\mathrm{q}}$ appears when the traction power supply system is in parallel with power system transmission line.

In Fig. 8, there is

$$
I_{\mathrm{q}} Z_{\mathrm{q}}=Z_{\mathrm{d}} I_{\mathrm{d}} \text {. }
$$
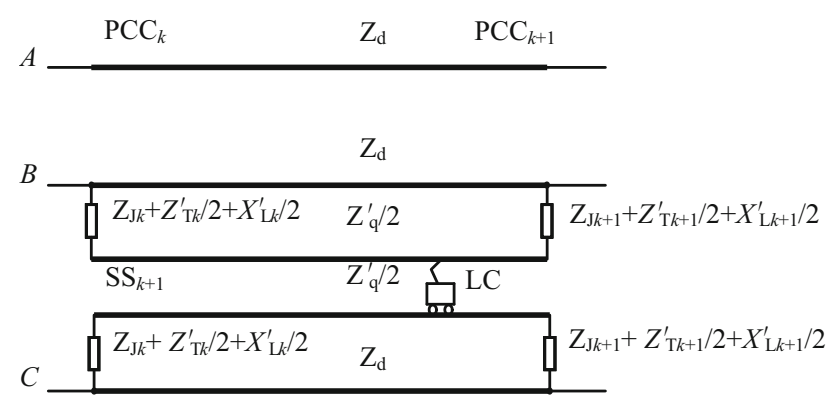

Fig. 7 Equivalent three-phase circuit of the bilateral power supply system

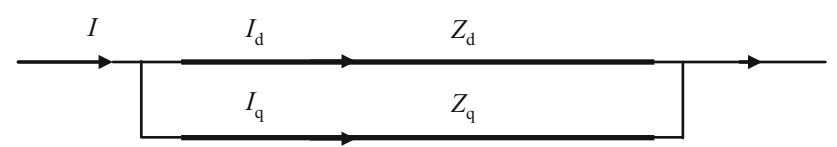

Fig. 8 Current balance diagram
Assume that $\eta$ is the ratio of traction power supply system impedance and power system transmission line impedance, converted to the same voltage level, i.e.,

$\eta=\left|\frac{Z_{\mathrm{q}}}{Z_{\mathrm{d}}}\right|$.

Then, the amount of equalizing current can be represented by the ratio of equalizing current to power transmission line current and it is called the relative value of equalizing current. Based on Eqs. (8) and (9), the following relationship can be derived:

$\left|\frac{I_{\mathrm{q}}}{I_{\mathrm{d}}}\right|=\left|\frac{Z_{\mathrm{d}}}{Z_{\mathrm{q}}}\right|=\frac{1}{\eta}$.

In other words, the relative value of equalizing current is the reciprocal of impedance ratio $\eta$, and is inversely proportional to the impedance of the traction power supply system and is proportional to the impedance of the power system transmission line. If $Z_{\mathrm{J} k}=Z_{\mathrm{J} k+1}=Z_{\mathrm{J}}$ is the inlet wire impedance, $Z_{\mathrm{T} k}=Z_{\mathrm{T} k+1}=Z_{\mathrm{T}}$ is the TT leakage reactance, and $Z_{\mathrm{L} k}=Z_{\mathrm{L} k+1}=Z_{\mathrm{L}}$ is reactance of the series reactor, on the traction side, then

$\eta=\left|\frac{2 Z_{\mathrm{J}}+\left(Z_{\mathrm{T}}+X_{\mathrm{L}}+\frac{1}{2} Z_{\mathrm{q}}\right) k_{\mathrm{T}}^{2}}{Z_{\mathrm{d}}}\right|$,

where $k_{\mathrm{T}}$ is the TT voltage ratio (ratio of power system line voltage to traction bus rated voltage).

Assume that the length of transmission lines in $220 \mathrm{kV}$ power system between $\mathrm{PCC}_{k}$ and $\mathrm{PCC}_{k+1}$ is $50 \mathrm{~km}$ and the length of transmission line between $\mathrm{PCC}_{k}\left(\mathrm{PCC}_{k+1}\right)$ to traction substation $\mathrm{SS}_{k}\left(\mathrm{SS}_{k+1}\right)$ is $10 \mathrm{~km}$. The twin-bundled conductors are used as transmission line in $220 \mathrm{kV}$ power system, and the unit-length impedance $Z_{0}=0.05+\mathrm{j} 0.33 \Omega / \mathrm{km}$. The TTs $\mathrm{TT}_{k}$ and $\mathrm{TT}_{k+1}$ are single-phase transformer with 31.5 MVA rated capacity (the rated current on traction side is $1,145 \mathrm{~A}$ ), the shortcircuit impedances (leakage reactance) are $10.5 \%$, and the transformation leakage reactance converted to traction side $Z_{\mathrm{T}}=0.2134+\mathrm{j} 2.52 \Omega$. The distance between adjacent traction substations is $50 \mathrm{~km}$. The no-load voltage of direct traction power supply network is $27.5 \mathrm{kV}$. For a singletrack railway, a single-chain suspension traction network impedance $z=0.2325+\mathrm{j} 0.515 \Omega / \mathrm{km}$. Assume that the series reactors' reactance $L_{k}$ and $L_{k+1}$ are $k$ times the TT leak reactance, that is, $X_{\mathrm{L}}=k X_{\mathrm{T}}, k \geq 0$.

The partial relationships between $k$ and $\eta$ are shown in Table 1.

It can be seen from Table 1 that if there is no series reactor $(k=0)$ in a direct, bilateral supply network where the voltage of power system is $220 \mathrm{kV}$ and if the twinbundled conductors are used, the impedance ratio $\eta=64$; that is, the relative value of the equalizing current is $1 / 64$. In other words, the ratio of the penetrating power of the 
Table 1 Relationships between $k$ and $\eta$

\begin{tabular}{llllll}
\hline$k$ & 0 & 1 & 2 & 3 & 3.92 \\
\hline$\eta$ & 64 & 73 & 82 & 91 & 100 \\
\hline
\end{tabular}

traction network to the transmission power of the transmission lines is 1:64. It can be concluded that if there is no series reactor, there will be large equalizing current in the mode of bilateral supply and the penetrating power as well, resulting in a waste of traction power supply equipment capacity and causing power energy metering problem. In the former Soviet Union, increasing traction network voltage level through series capacitor compensation (SCC) in their traction feeder caused even higher equalizing current (or penetrating power) [15].

Furthermore, if the series reactor is present $(k>0)$, and the equalizing current must be less than $1 \%$, that is, $\eta \geq 100$ and $k \geq 3.92$, then the series reactor reactance should be at least 3.92 times the TT leakage reactance, and its capacity is about 13 MVA. If the TT has a high leakage reactance, the short-circuit impedance ratio is $51.66 \%$. Therefore, the series reactor can effectively reduce equalizing current in the mode of bilateral supply.

It can also be concluded from Eq. (11) that the higher the power system voltage is (i.e., the larger $k_{\mathrm{T}}$ is), the smaller the equalizing current in the mode of bilateral supply will be.

\subsection{Voltage loss}

A voltage loss $\Delta U$ is introduced by a load current $I$ with a power factor $\cos \varphi$, passing through the impedance $Z=$ $R+\mathrm{j} X$. It is the arithmetic difference of voltages between two terminals of the impedance $Z$, and can be described as follows:

$$
\begin{aligned}
\Delta U= & U_{1}+I(R \cos \varphi+X \sin \varphi) \\
& -\sqrt{U_{1}^{2}-[I(R \sin \varphi-X \cos \varphi)]^{2}},
\end{aligned}
$$

where $U_{1}$ is the traction bus voltage and takes $27.5 \mathrm{kV} ; R$ is the TT resistance; $X=X_{\mathrm{T}}+X_{\mathrm{L}}=(1+k) X_{\mathrm{T}}$, in which $X_{\mathrm{T}}$ is the TT leakage reactance and $X_{\mathrm{L}}$ is the reactance of series reactor.

Taking a high-speed railway line as an example, where the TT is single-phase transformer, its short-circuit impedance ratio (leakage reactance) is $10.5 \%$, and the rated capacity is $31.5 \mathrm{MVA}$. The power factor of an $\mathrm{AC}-$ DC-AC locomotive $\cos \varphi_{0}=0.993$ (lag, i.e., $\varphi_{0}=6.78$ and $\sin \varphi_{0}=0.118$ ). Based on Eq. (12), the voltage losses can be calculated with different values of the series reactor, as shown in Table 2. The vector diagram of voltage loss is shown in Fig. 9.
Table 2 Voltage loss

\begin{tabular}{llllll}
\hline$k$ & 0 & 1 & 2 & 3 & 3.92 \\
\hline$\Delta U(\mathrm{~V})$ & 730 & 1,522 & 2,633 & 4,095 & 5,790 \\
\hline
\end{tabular}

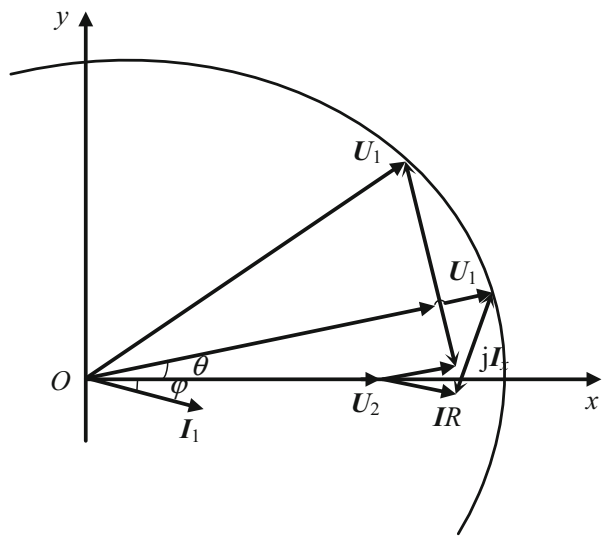

Fig. 9 Voltage drop diagram

From Tables 1 and 2, it can be seen that the impedance ratio $\eta$ is equal to 100 when $k=3.92$, and thus the equalizing current meets the requirement of being less than $1 \%$. However, the voltage loss of traction bus is increased from 730 to $5,790 \mathrm{~V}$. In order to have a proper voltage level, it is required to change the traction load power factor or adjust the train AC-DC-AC main circuit or use the adjustable shunt reactive power generating device (such as $\mathrm{SVG}$, or use a combination of the above approaches.

Based on the previous example in which the twin-bundled conductors are used in $220 \mathrm{kV}$ power transmission lines and the voltage of direct, bilateral traction power supply network is $27.5 \mathrm{kV}$, two design goals are discussed as follows, where the equalizing current $\leq 1 \%$ is required and the impedance ratio $\eta=100$.

Design goal I: Assume that the power factor of the load current of high-speed railway $\cos \varphi_{0}=0.993$ (lag), and the permissible voltage loss at substation at the rated condition $\Delta U_{0}=730 \mathrm{~V}$.

Design goal II: Based on the power factor of the load current of low-speed railway, $\cos \varphi_{0}=0.8(\mathrm{lag})$, the permissible voltage loss at substation at the rated condition $\Delta U_{0}=2,012 \mathrm{~V}$, that is,

$$
\left.\begin{array}{l}
\eta \geq 100 \\
\Delta U \leq \Delta U_{0}
\end{array}\right\}
$$

where $\eta$ is given by Eq. (11) and $\Delta U$ is given by Eq. (12).

Table 3 shows the design goals and the corresponding results. 
Table 3 Design goals and results

\begin{tabular}{lll}
\hline Indicator & $\Delta U_{0}=730 \mathrm{~V}$ & $\Delta U_{0}=2,012 \mathrm{~V}$ \\
\hline$\eta$ & 100 & 100 \\
$k$ & 3.92 & 3.92 \\
$\varphi_{\mathrm{c}}$ & $-13.29($ lead $)$ & $-8.53($ lead $)$ \\
$\cos \varphi_{\mathrm{c}}$ & $0.973($ lead) & $0.989($ lead) \\
$\sin \varphi_{\mathrm{c}}$ & $-0.230($ lead) & $-0.148($ lead) \\
\hline
\end{tabular}

It can be seen from Table 3 that if the impedance of the series reactor is 3.92 times the leakage reactance of the TT, the equalizing current ratio will be less than $1 \%$. If the load power factor is changed from 0.993 (lag) to 0.973 (lead), then the voltage loss under the rated condition at traction substation will be less than $730 \mathrm{~V}$ which corresponds to the power factor 0.993 (lag). In this case, the capacitive reactive power will account for $23 \%$ in load, which is difficult to be achieved. Similarly, if the power factor of the load is changed from 0.993 (lag) to 0.989 (lead), the voltage loss under the rated condition will be less than 2,012 $\mathrm{V}$ which corresponds to the power factor 0.8 (lag) at low-speed railway, and the capacitive reactive power will account for $14.8 \%$ in load. This is easier to be realized.

Furthermore, space can be saved if the series reactor is merged into the TT, resulting in a more compact structure and a high-leakage-reactance transformer in which the value of leakage reactance $\left(X_{k}\right)$ equals the value of the leakage reactance of the original TT $\left(X_{\mathrm{T} k}\right)$ plus the leakage reactance of reactor $\left(X_{\mathrm{L} k}\right)$. The short-circuit impedance of this high-leakage-reactance transformer is $51.66 \%$ in the above example.

Compared with the unilateral power supply, the bilateral power supply has advantages of higher voltage level, larger supply capacity, and lower power loss. The disadvantage is the presence of equalizing current. The purpose of developing a new bilateral power supply is to eliminate phase split at section post and to reduce the equalizing current. It has been shown that by using a reactor in series with the traction feeder and by changing the load power factor, the equalizing current can be effectively suppressed. The voltage loss due to the series reactor can also be reduced or even be eliminated. A proper voltage level and the power supply ability are thus able to be maintained.

With a reactor in series with the feeder of a traction substation, the traction loads in a traction network can be redistributed based on the impedance proportion in each of substations. By doing so, the traction substation capacities along the line can be optimized according to the distribution of the power system capacity, and the TT load rate can be improved. At the same time, the short-circuit current will be decreased and its impacts on the TT, breaker, and other devices will be reduced. Thus, selection of circuit breaker, and cut-off of faults will be easier, and the operational reliability will be higher.

Bilateral short-circuit fault can be decomposed into unilateral power supply failure. It can also be tackled by approaches discussed in Sect. 3 below.

A bilateral power supply system for electrified railway is similar to a closed-loop power distribution system. Therefore, further study should be done by taking both electrified railway and power system into considerations $[16,17]$.

\section{Segmental power supply and measurement control}

The segmental power supply is an effective approach in detecting, isolating, and removing fault in time so that a fault can be limited to a minimum level and its impact to a minimum degree, so that the system controllability and maintainability can be improved. The segmental supply modes in bilateral power supply system can be categorized as follows:

(1) At the section post, the bilateral longitudinal traction network is divided into two segments; and each segment is equal to the original power supply arm, that is, the natural segments.

(2) In a double-track railway, the up and down line will naturally be segmented. For example, for a unilateral supply, the traction network is divided into two segments in the transverse direction; in a bilateral power supply mode, the traction network between two adjacent substations is divided into four segments.

(3) Auto-transformer (AT) section is regarded as a segment in AT power supply system.

Segmental power supply in a power supply system can be further categorized, based on the real situation. For example, take the interval $(10 \mathrm{~km}$ or so) as a unit in a section for longitudinal traction network segments. Moreover, a catenary anchor segment can be described as the smallest segment, and a power arm in unilateral power supply network can be described as one of the largest segments.

Two segment posts are deployed at both ends of a segment. Within each post, there are voltage transformers where $U_{\mathrm{i}}$ and $U_{\mathrm{o}}$ are measured voltages. Sectionalizers $S_{\mathrm{i}}\left(S_{\mathrm{o}}\right)$ are connected in parallel with breakers $K_{\mathrm{i}}\left(K_{\mathrm{o}}\right)$ and in series with current transformers (where $I_{\mathrm{i}}$ and $I_{\mathrm{o}}$ are measured currents), to ensure the measurability and controllability. The segmental power supply diagram is shown in Fig. 10. 


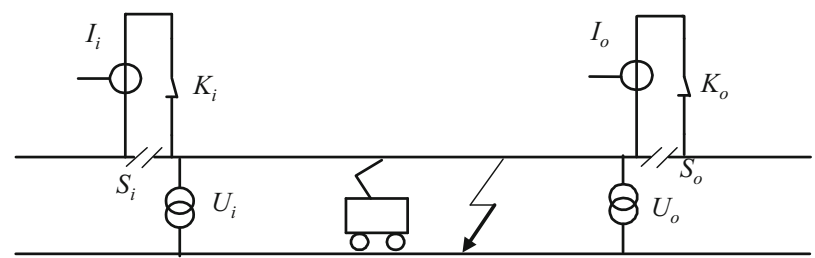

Fig. 10 Segmental power supply diagram

\subsection{Electrified train locating and operation status monitoring}

In Fig. 10, it is assumed that the input current $I_{\mathrm{i}}$ and output current $I_{\mathrm{o}}$ of each segment are positive, and the voltages $U_{\mathrm{i}}$ and $U_{\mathrm{o}}$ are all in the normal range.

If $I_{\mathrm{i}}-I_{\mathrm{o}}=0$, there is no electrified train in the segment. If $I_{\mathrm{i}}-I_{\mathrm{O}}>0$, there is a moving train in traction in the segment.

If $I_{\mathrm{i}}-I_{\mathrm{o}}<0$, there is a moving train in regenerative breaking in the segment.

\subsection{Symbol definition of failure power flow} and traction network fault identification

If terminal voltages $U_{\mathrm{i}}$ or $U_{\mathrm{o}}$ of each segment are below their normal values, it is identified as a fault condition. In Fig. 10, we assume that the symbol value for no-load power flow is denoted by 0 , that for failure power flow into the segment is denoted by 1 , and that for failure power flow out from the segment is denoted by -1 . Then, the sum of symbol values of each terminal of a segment can be calculated.

If $p=0$, there is no fault in the segment.

If $p=1$, there is a ground fault at the terminal of the segment with a symbol value of 1 , and there is an open circuit fault at the terminal of the segment with the symbol value of 0 .

If $p=2$, there are ground faults at both terminals of the segment.

Composite faults can be identified in a similar way. This approach can also be used in the AT power supply mode. Besides, segmental power supply can provide benefits for AT traction network impedance linearization, impedance measurement, and fault diagnosis. This topic will not be discussed in this paper.

\section{The system, its economy and reliability}

Except that the bilateral power supply was used in former Soviet Union, unilateral power supply is widely used in the electrified railways with industrial frequency single-phase

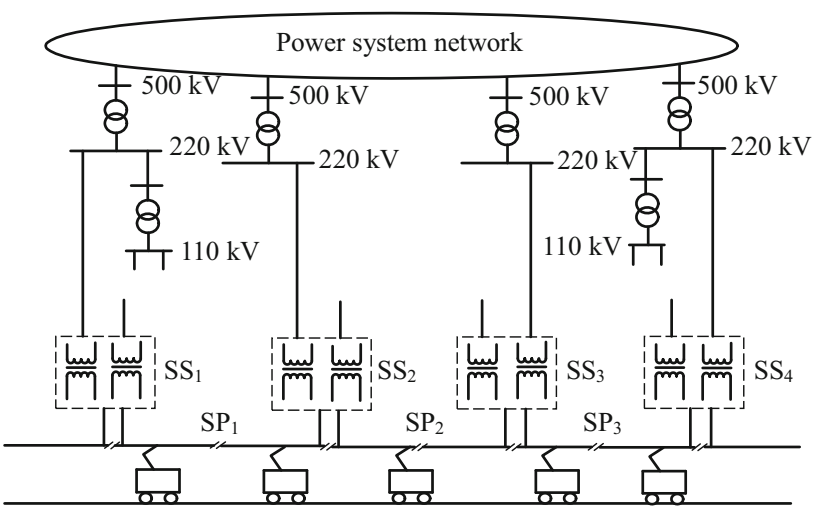

Fig. 11 Traditional traction power supply system

AC power supply system around the world. In China, almost all the high-speed railway traction substations adopt VV- or VX-connected TT. The connection diagram of traction power supply system and power system is shown in Fig. 11. Adopting unilateral supply mode and connection to power grid in a way of phase rotation, phase splits are set up at the exit of a traction substation and at a section post. Therefore, there are two-phase splits in the power supply range for each of substations.

There are two kinds of situations to be considered to avoid phase split. One consideration should be given by adopting single-phase TT at substation, together with a cophase power supply device, which can ultimately eliminate phase split at substations. The primary goal is to compensate the negative sequence current and thus conforms to the national standard. Another should be given by adopting the bilateral supply mode at section post so as to avoid phase split. As the power system operates in closed loop with the highest voltage level and other open-loop networks, the key is to reduce the equalizing current due to the traction system in parallel with the power system to an allowable level. Such a new traction power supply system allows the industrial frequency single-phase AC power supply system of an electrified railway to achieve no phase split. As shown in Fig. 12, SS represents a traction substation where a single-phase TT and a CPD work together; or only a single-phase transformer is used when compensation is not needed. SP represents a section post which connects both sides of the traction network.

As discussed in Sect. 1.3, a CPD can work at either mode 1 or mode 2 . However, it will always provide power which is proportional to the total (active) power of a traction substation or its rated power, in a certain range. The distribution of the traction load $s_{\mathrm{L}}(t)$ to each of the traction substations, denoted by $s_{\mathrm{ss}}(t)$, will not be affected as well. In other words, when an electrified railway adopts the industrial frequency single-phase AC traction power system with co-phase power supply, the distribution of traction load $s_{\mathrm{L}}(t)$ to each of substation $\left(s_{\mathrm{ss}}(t)\right)$ depends 


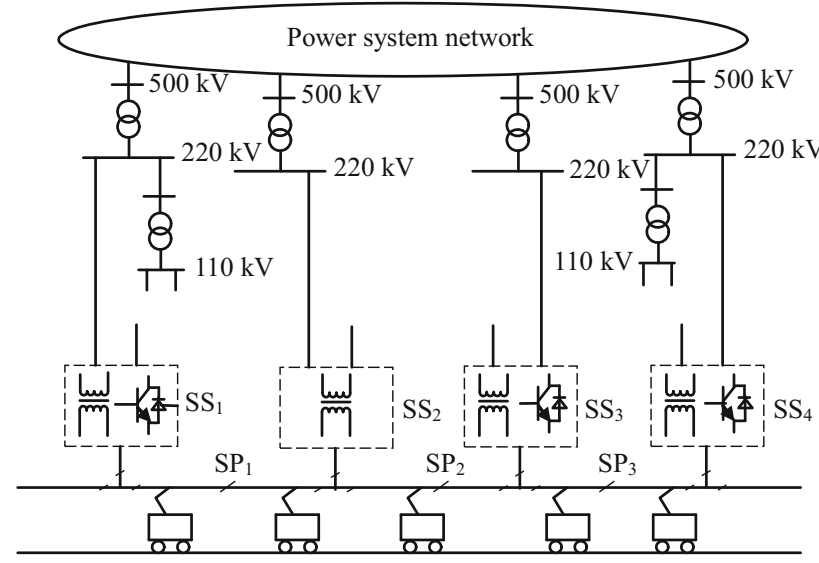

Fig. 12 New generation traction power supply system

only on the equivalent network model of the power system and the traction power supply system [5].

The use of the proposed new generation traction power supply system is especially beneficial for achieving the best capacity and optimal design of numbers and locations of traction substations [18]. If an adjustable reactive power compensation device such as SVG is installed at the section post, then the functions of anti-icing and anti-melting can be achieved [19]. Furthermore, by adding a CPD, series reactor and other segmental supply and monitoring equipment where the CPD plays a central role by adopting the combined co-phase power supply scheme, the required capacity and the one-time investment can be reduced to their minimum. Even the life-cycle cost will approach the cost of auto-passing phase-split device on the ground. Other benefits include

(1) Phase-split elimination will be able to allow train speed increase and improve the line passing capacity significantly [20].

(2) Improving the load factor and capacity utilization to a great extent. Pilot test and analysis have shown that the installed capacity of the TT can be reduced 1 to 2 capacity levels and thus the power resources and operating cost are saved.

(3) Saving energy significantly. While system power loss is reduced, it is easier for renewable energy that one train locomotive generates to be used by the other trains or to be put back to the connected power system.

Looking at the traction power supply mode in Germany, the power supply frequency is different from industrial frequency $(50 / 60 \mathrm{~Hz})$ of power systems. Therefore, the electrified railway in Germany either uses its own power source or takes the power system source through ADA conversion, and thus the power supply network is complex and the cost is high, so that it is difficult to be used widely.
In the latter case, the power at the traction substation is supplied by the power system which comprises a threephase TT and a three-phase single-phase ADA. Similar to the CPD as described previously, this system has a small overload capacity. To meet the needs of a peak load, its capacity would have to be greatly increased. In Example 1 at Sect. 1.3, the co-phase compensation capacity for the combined co-phase power supply system requires 10 MVA, while the ADA capacity for the German system needs 50 MVA. In Example 2 at Sect. 1.3, the former needs $20 \mathrm{MVA}$ and the latter is $120 \mathrm{MVA}$. The high cost of the ADA and the large capacity requirement would surely lead to a higher system investment.

Therefore, the co-phase power supply without phase splits can be achieved for an electrified railway line with a minimal investment by integrating the combined co-phase power supply technology at traction substation, the new bilateral power supply, segmental power supply, and synchronous measurement and control technology on the traction network. In other words, only a fraction of cost of the German system is needed to achieve the co-phase power supply.

At the same time, this new generation traction power supply system provides the enhanced reliability as listed below:

(1) The combined co-phase power supply system is the single-phase TT based, supplemented with the CPD. Thus, when the compensation device is in maintenance status, the system can continue to work properly with the help of the short-term overload ability of the TT.

(2) The arrangement of standby CPDs is flexible so as to make the system more reliable. Figure 13 shows an example of a single-phase and single-phase combined co-phase power supply system in Fig. 4, where the TT adopts traditional $100 \%$ standby mode and the CPDs adopt ' $\mathrm{m} / \mathrm{n}$ ' system. This means that at least

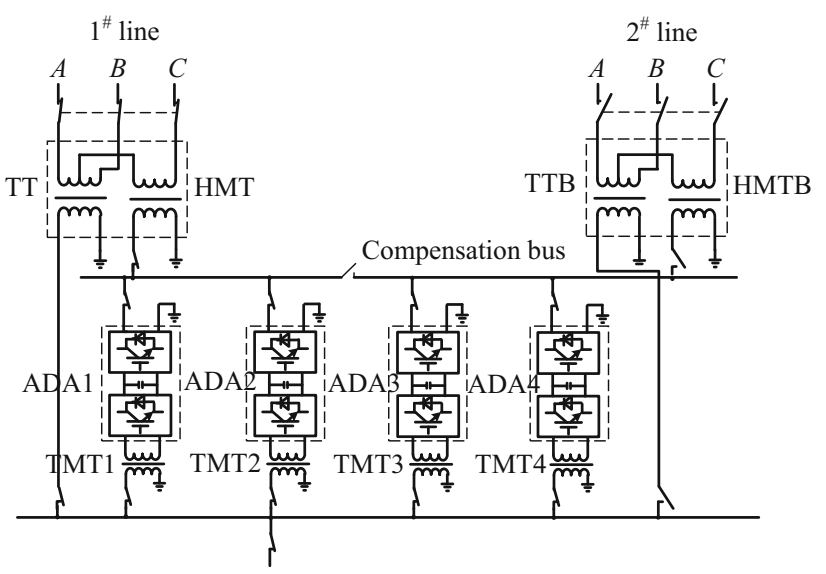

Fig. 13 Co-phase compensation devices using 3/4 system or 2/4 system 
$m$ units among $n$ units are working properly. In this example, the compensation device is using ' $3 / 4$ ' system or '2/4' system (Fig. 13).

(3) The bilateral supply system is equivalent to the dual power source system and thus its reliability is higher than that of the unilateral supply system.

(4) Segmental power supply and measurement control technology can improve controllability and maintainability of a power supply system, as discussed in Sect. 3.

(5) Avoiding faults because of auto-passing phase split of a train, which do exist in the current system.

\section{Conclusion}

In this paper, a new generation traction power supply system, that is, a co-phase traction power supply system without phase split for industrial frequency single-phase AC electrified railways, is presented. The techniques of combined co-phase supply, bilateral power supply, segmental power supply, and measurement control are discussed. The main conclusions can be drawn as follows:

(1) A combined co-phase power supply system, which can work with a single-phase and three-phase combined module, or a single-phase and single-phase combined module, is able to eliminate phase split at the exit of a substation. At the same time, the negative sequence current is compensated to meet the national standard requirement of the negative sequence reactive power allowable value. The optimal capacity matching between the CPD and the single-phase TT is also achievable.

(2) The new bilateral power supply technology can be used to eliminate the phase split at section posts. By connecting a reactor in series with the traction feeder, the equalizing current and its impact to the power grid can be reduced. Lastly, the power factor can be adjusted to ensure a proper voltage level of traction network.

(3) The segmental power supply essentially divides the power supply arm into segments, and thus faults can be detected quickly and accurately using the synchronous measurement and control technique. As a result, the fault impact is limited to a lesser extent.

(4) The new generation of traction power supply system is more reliable and economic.

Acknowledgments This work was supported by the National Natural Science Funds of China (Nos. 51307143 and 51307142) and Technology Research and Development Program of China Railway Corporation (No. 2014J009-B).
Open Access This article is distributed under the terms of the Creative Commons Attribution License which permits any use, distribution, and reproduction in any medium, provided the original author(s) and the source are credited.

\section{References}

1. Cao JY (1956) The way of electrified railway in China. People's Daily, Nov. 26, China

2. Cao JY (1983) Power supply system of electrified railway. Press of Chinese Railway, Beijing, pp 106-109

3. Li QZ, He JM (2012) Analysis of traction power supply system (Version III). Press of Southwest Jiaotong University, Chengdu, pp 155-158, 59-267

4. Wu JQ (2010) Pantograph-catenary system. Press of Southwest Jiaotong University, Chengdu, pp 114-116

5. Li QZ, Zhang JS, He WJ (1988) Research on new power system for heavy haul traction. J China Railw Soc 4:23-31

6. Li QZ, Lian JS, Gao SB (2006) Electrified engineering of high speed railway. Press of Southwest Jiaotong University, Chengdu, pp 155-166

7. Li QZ (2006) Electrical analysis of traction substation and technology of comprehensive compensation. Press of Chinese Railway, Beijing, pp 72-93

8. National Technical Committee on Voltages, Current Ratings and Frequencies of Standardization Administration of China (2001) Application manual of voltages, current, frequency and power quality standards. China Electric Power Press, Beijing, pp 129-228

9. Li QZ, He JM, Jie SF (2011) Analysis and control of power quality of electrified railway. Press of Southwest Jiaotong University, Chengdu, pp 51-98

10. Arai Koichi (1980) Balancing circuit for single phase load with scalene Scott connected transformer. Res Inf Railw Technol 37(6):23-28

11. Standardization Administration of the People's Republic of China (2008) Power quality three-phase voltage unbalance degree, GB/ T15543-2008

12. Xie SF, Li QZ, He JM (2003) Study on temperature rise and loss of life of traction transformer. Electr Drive Locomot 4:15-17

13. Shu Z, Xie S, Li Q (2011) Single-phase back-to-back converter for active power balancing, reactive power compensation and harmonic filtering in traction power system. IEEE Trans Power Electron 26(2):334-343

14. Mark Walter GK (1989) Power supply of electrified railway (trans: Yuan ZF, He QG). Press of Southwest Jiaotong University, Chengdu, pp 141-145

15. Bala Durning BJ (1982) Capacitance compensation device (trans: Zhang JS, He HT). Press of Chinese Railway, Beijing, pp 42-50

16. Tang XH (2006) Protection setting of loop power grid with voltage of $110 \mathrm{kV}$ and above. Rural Electrif 27(9):28-30

17. Wang W, Gao K (2010) Analysis of loop problem of Beijing power grid. Water Resour Hydro power Northeast China 12:58-61

18. Li QZ, He JM, Li SH (1992) Study of the optimization design for traction power supply system. J Southwest Jiaotong Univ 27(1):83-90

19. Li QZ, Guo L, Shu ZL et al (2013) On-line anti-icing technology for catenary of electrified railway. J China Railw Soc $35(10): 46-51$

20. Guo JC (2013) Research on power-supply technology applying on shenshuo railway. Electr Drive Locomot 4:47-50 